\title{
Usefulness and limitations of E-cadherin and $\beta$-catenin in the classification of breast carcinomas in situ with mixed pattern
}

Douglas S Gomes', Simone S Porto ${ }^{1}$, Rafael M Rocha ${ }^{2}$ and Helenice Gobbi ${ }^{*}$

\begin{abstract}
Background: The distinction between lobular neoplasia of the breast and ductal carcinoma in situ has important therapeutic implications. In some cases, it is very difficult to determine whether the morphology of the lesion is ductal or lobular. The aim of this study was to evaluate the value of E-cadherin and $\beta$-catenin expression through the immunophenotypical characterization of carcinoma in situ with mixed pattern (CISM).

Methods: A total of 25 cases of CISM were analyzed considering cytology/mixed architecture (ductal and lobular), nuclear pleomorphism, loss of cell cohesion, and presence of comedonecrosis. The immunophenotype pattern was considered E-cadherin positive and $\beta$-catenin positive, or negative.

Results: Nineteen (76\%) cases presented a mixed cytology and / or architectural pattern, two (8\%) presented nuclear pleomorphism, two (8\%) presented mixed cytology and nuclear pleomorphism, and two (8\%) presented comedonecrosis and nuclear pleomorphism. A complete positivity for E-cadherin and $\beta$-catenin was observed in 11 cases (44\%). In one case, the lesion was negative for both markers and showed nuclear pleomorphis. Thirteen lesions showed negative staining in areas of lobular cytology and positive staining in cells presenting the ductal pattern.

Conclusions: The expression of E-cadherin and $\beta$-catenin, combined with cytological and architectural analysis, may highlight different immunophenotypes and improve classification of CISM.

Virtual Slides: The virtual slide(s) for this article can be found here: http://www.diagnosticpathology.diagnomx.eu/vs/ 1693384202970681
\end{abstract}

Keywords: E-cadherin, $\beta$-catenin, Breast cancer, Lobular neoplasia, Ductal carcinoma in situ, Immunohistochemistry

\section{Additional non-English language abstract - Portuguese}

Introdução: A distinção entre neoplasia lobular e carcinoma ductal in situ tem importantes implicações terapêuticas. No entanto, em alguns casos, é muito difícil determinar se a morfologia da lesão é ductal ou lobular. O objetivo deste estudo foi avaliar a expressão de E-caderina e $\beta$-catenina na caracterização imunofenotípica dos carcinomas in situ de padrão misto (CISM).

Métodos: Um total de vinte e cinco casos de CISM foram analisados considerando a citologia/arquitetura mista (ductal e lobular), pleomorfismo nuclear e presença de comedonecrose. A expressão imuno-histoquímica foi considerada positiva para E-caderina e $\beta$-catenina, ou negativa.

(Continued on next page)

\footnotetext{
* Correspondence: hgobbi@medicina.ufmg.br

'Breast Pathology Laboratory, School of Medicine, Federal University of Minas

Gerais (UFMG), Av. Professor Alfredo Balena, 190, Belo Horizonte, Minas

Gerais 30130-100, Brazil

Full list of author information is available at the end of the article
}

\section{Biomed Central}

(c) 2013 Gomes et al.; licensee BioMed Central Ltd. This is an Open Access article distributed under the terms of the Creative Commons Attribution License (http://creativecommons.org/licenses/by/2.0), which permits unrestricted use, distribution, and reproduction in any medium, provided the original work is properly cited. 
(Continued from previous page)

Resultados: Dezenove (76\%) casos apresentavam somente citologia e/ou padrão arquitetural misto (ductal e lobular), dois casos (8\%) apresentaram somente pleomorfismo nuclear, dois casos (8\%) apresentavam citologia mista e pleomorfismo nuclear, e dois casos (8\%) tinham comedonecrose e pleomorfismo nuclear. Uma positividade completa para E-caderina e $\beta$-catenina foi observada em 11 casos (44\%). Em um caso a lesão foi negativa para ambos marcadores e apresentava pleomorfismo nuclear e comedonecrose. Em 13 lesões o imunofenótipo foi negativo em áreas lobulares e positivo em áreas ductais.

Conclusão: A caracterização imunofenotípica com E-caderina e $\beta$-catenina, combinada com a análise citológica e arquitetural, pode destacar diferentes imunofenótipos e auxiliar na classificação dos CISM.

\section{Background}

In situ breast carcinomas are classified, according to their morphology, as ductal carcinoma in situ (DCIS) or lobular neoplasia (LN), which includes lobular carcinoma in situ (LCIS) and atypical lobular hyperplasia (ALH). According to the 2012 WHO classification of tumors of the breast, classic LCIS is diagnosed when more than half of the acini of a lobular unit are distended and distorted by a dyshesive proliferation of cells with small, uniform nuclei. Lesser involvement by the characteristic cells is diagnosed as ALH. Lesions that show marked nuclear pleomorphism, with or without apocrine features and comedonecrosis are referred as pleomorphic LCIS (PLCIS) [1].

In some cases, the diagnostic criteria based on the morphology of LN is not clear, leading to mistaken diagnosis of intraductal proliferative lesions. The main differential diagnoses of lobular neoplasia are: LN with solid low-grade DCIS, PLCIS and high-grade DCIS. Some in situ carcinomas present unusual cytological and / or architectural features, making it difficult to determine whether the proliferation is lobular or ductal. This group has been called carcinomas in situ with a mixed or indeterminate pattern (CISM) [2,3].

The differential diagnosis of the CISM carries some important implications. Patients with LN are usually clinically monitored and can be offered tamoxifen as a prophylactic therapy to prevent the development of invasive carcinoma $[4,5]$. On other hand, patients with DCIS should be treated by surgical removal of the lesion, with clear margins followed by radiotherapy, or mastectomy [6]. When diagnosed by core biopsy, DCIS should be treated with complete excision of the lesion. However, the clinical significance and therapeutic implications of finding LN in core biopsy specimens are still controversial $[7,8]$.

The diagnosis of CISM is extremely rare and studies assessing the differential diagnosis of these lesions are scarce and include only a few patients. The largest series reported between 12 and 28 cases [9,10]. Previous studies by our group identified $0.08 \%$ of CISM among breast biopsies performed in our general hospital [11]. Although rare, when analyzed under light microscope, the CISM lesions are difficult to diagnose and there is lack of epidemiological data linked to their biological behavior.

A great progress in the diagnosis of these lesions came with the observation that almost all cases of LN and invasive lobular carcinoma (ILC) lose the immunohistochemistry (IHC) signal for E-cadherin and $\beta$-catenin expression in the cytoplasm membrane, whereas the expression of these proteins is maintained in both in situ and invasive ductal carcinomas $[3,12,13]$. The cadherins comprise a large number of adhesion molecules localized in the intercellular junctions, keeping cells connected through homophilic protein-protein interactions. The observation that cadherins play an important role in the establishment of the epithelial phenotype, cell migration, cell differentiation, and tumor dissemination has stimulated great interest in this family of adhesion molecules. Among them is the Human Epithelial Cadherin (E-cadherin), a calcium-dependent transmembrane glycoprotein directly involved in the process of cell adhesion [14]. The $\alpha, \beta, p$, and $\gamma$ catenins play important roles in intercellular signal transduction. The $\beta$-catenin, specifically, binds to the cytoplasmatic portion of the E-cadherin and to the structure of actin microfilaments of the cytoskeleton as well, being involved in cell adhesion $[15,16]$. The E-cadherin gene mutation is the major mechanism responsible for its inactivation in cancer cells and is associated with other carcinomas, such as hepatocellular carcinoma, diffuse-type gastric cancer, thyroid and colorectal cancer $[16,17]$. Another route resulting in inactivation of E-cadherin is attributed to dysfunctional promoter activity or DNA methylation at the promoter region $[17,18]$.

The aim of this study was to evaluate the expression of E-cadherin and $\beta$-catenin for the immunophenotypical characterization of carcinomas in situ with mixed pattern, and identify potential morphological patterns that could assist in the diagnosis of the different types of CISM lesions.

\section{Methods}

This is a retrospective, descriptive study that analyzed 25 cases of breast biopsies (wide local excision or mastectomy) performed between 1999 and 2011. The study 
analyzed the histopathological reports and slides available at the Laboratory of Breast Pathology at the School of Medicine at the Federal University of Minas Gerais (UFMG), Brazil. We selected one or more slides stained with hematoxylin and eosin (HE) and which were representative of each diagnosis of in situ carcinoma with mixed pattern. The slides were analyzed simultaneously by two of the authors (HG and DSG) using a dual-view microscope and classified according to the standard morphological patterns and immunohistochemical expression of E-cadherin and $\beta$-catenin. Cases without available slides and / or paraffin blocks were excluded from the study. The study was approved by the UFMG research ethics committee.

\section{Morphological evaluation}

In situ lesions matching the LN morphological pattern were characterized according to the proliferation of generally small, dyshesive cells, with uniform round nuclei and clear cytoplasm. The acini are partially or completely expanded, but the lobular architecture is maintained [1]. Lesions classified as DCIS presented proliferation of monomorphic cells with regular distribution, and hyperchromatic nuclei forming regular secondary, rounded, and uniform lumens. The in situ lesions characterized as mixed pattern presented cytological or architectural features common to the ductal and lobular lesions and were classified into three main patterns according to criteria previously described by Jacobs et al. [3]: Group 1 - those presenting architectural and cytological findings of LN but with areas of comedo-type necrosis; Group 2 - those with CISM lesions characterized by small and uniform cells, either growing in a solid pattern with focal microacinar-like structures but with cellular dyshesion, or growing in a mosaic pattern with occasional intracytoplasmic vacuoles; Group 3 - those with marked cellular pleomorphism and nuclear atypia, however, the LN discohesive pattern remains.

\section{Immunohistochemical evaluation}

Sequential $5 \mu \mathrm{m}$ thick histological sections were obtained from the paraffin blocks from the breast specimens and mounted on silanized slides. Sections were deparaffinized in two consecutive baths of xylene, for 20 minutes each, and rehydrated in ethanol series with decreasing concentrations and finally in distilled water. For antigen retrieval, a buffer solution of $10 \mathrm{mM}$ citrate $\mathrm{pH} 6.0$ was used in an electrical pressure-cooker. Immunohistochemistry was performed automatically using Ventana Benchmark XT equipment (Ventana Medical Systems Inc., Tucson, AZ, USA). E-cadherin (clone 36) and $\beta$-catenin (clone 18) antibodies were used, at titers of $1: 600$ and 1:800, respectively. Antibodies were purchased from BD Transduction (cat\# C19220), San Jose, CA, USA.

The non-biotinylated polymer system (Novolink ${ }^{\circ}$, Leica Microsystens) technique was used for reaction amplification. A diaminobenzidine (DAB) solution was used as chromogen and the slides were counter-stained using Harris hematoxylin. External positive and negative controls were used. Normal ducts and lobules, adjacent
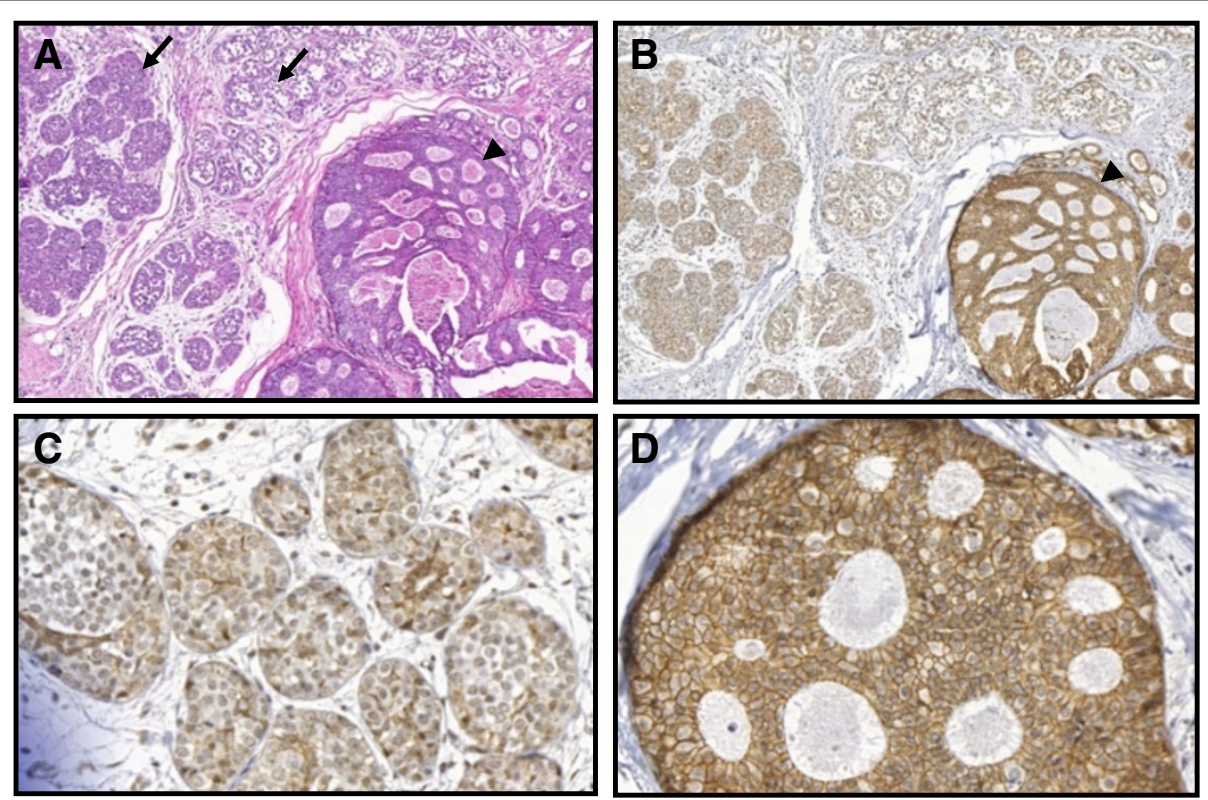

Figure 1 Case \# 1: Lobular neoplasia (arrows) and ductal carcinoma in situ of cribriform type (arrowheads) are present in the same breast field (hematoxylin and eosin; A - 100x). Cells of ductal carcinoma stain positive (B, $100 \times$ and $\mathbf{D}, 400 \times)$ and cells of lobular neoplasia are negative for E-cadherin (B, 100x and C, 400x). 
to the lesions and expressing E-cadherin and $\beta$-catenin in the epithelium, were used as internal controls.

Staining for E-cadherin and $\beta$-catenin was considered positive when the staining intensity around the entire circumference of the membrane was similar to that seen in the normal luminal epithelial cells. No staining was considered as negative (Figure 1).

\section{Results}

Twenty-five cases of CISM were identified from the Breast Pathology Laboratory during the study period. The average patient age was $52.7( \pm 11.5)$ years. Nineteen cases $(76 \%)$ presented morphological pattern showing cytology and / or architectural mixed pattern (ductal and lobular), two cases (8\%) showed lobular architectural pattern with nuclear pleomorphism, two cases (8\%) showed mixed cytology and nuclear pleomorphism, and two cases (8\%) showed comedonecrosis and nuclear pleomorphism (Table 1).

Immunohistochemistry for E-cadherin was performed in all 25 cases. Eleven cases (44\%) were positive for Ecadherin (Figure 2). Thirteen cases (52\%) showed mixed immunophenotype with positive E-cadherin staining the ductal cells and negative in the lobular areas. In one case, the cells were completely negative for E-cadherin.

In all cases in which both markers were analyzed (20 cases) the immunohistochemical results agreed with both E-cadherin and $\beta$-catenin. Immunohistochemistry for $\beta$-catenin was not performed in five cases due to sample processing artifacts and insufficient material for the preparation of new slides.

Nineteen cases were composed by small, uniform cells varying from low to intermediate nuclear grade, growing in solid pattern, with some microacinar-like structures admi-

Table 1 Morphology and immunophenotype of $\mathbf{2 5}$ breast carcinomas in situ with mixed pattern analyzed from breast biopsies

\begin{tabular}{|c|c|c|c|c|c|c|c|c|c|c|}
\hline \multirow[b]{2}{*}{ Case \# } & \multicolumn{3}{|c|}{$\begin{array}{l}\text { Morphological pattern } \\
\text { of in situ lesion }\end{array}$} & \multicolumn{3}{|c|}{ Morphology of in situ lesion with mixed pattern } & \multicolumn{2}{|c|}{$\begin{array}{c}\text { E-cadherin } \\
\text { immunophenotype }\end{array}$} & \multicolumn{2}{|c|}{$\begin{array}{c}\beta \text {-catenin } \\
\text { immunophenotype }\end{array}$} \\
\hline & Lobular & Ductal & Mixed & $\begin{array}{c}\text { Nuclear } \\
\text { pleomorphism }\end{array}$ & Comedonecrosis & $\begin{array}{l}\text { Mixed cytology } \\
\text { or architecture }\end{array}$ & $\begin{array}{l}\text { Lobular } \\
\text { areas }\end{array}$ & $\begin{array}{l}\text { Ductal } \\
\text { areas }\end{array}$ & $\begin{array}{l}\text { Lobular } \\
\text { areas }\end{array}$ & $\begin{array}{l}\text { Ductal } \\
\text { areas }\end{array}$ \\
\hline 1 & Yes & Yes & Yes & No & No & Yes & - & + & - & + \\
\hline 2 & No & No & Yes & No & No & Yes & - & + & - & + \\
\hline 3 & No & No & Yes & No & No & Yes & + & + & + & + \\
\hline 4 & No & No & Yes & No & No & Yes & + & + & + & + \\
\hline 5 & No & No & Yes & Yes & No & No & - & + & - & + \\
\hline 6 & No & No & Yes & No & No & Yes & + & + & + & + \\
\hline 7 & Yes & No & Yes & No & No & Yes & + & + & + & + \\
\hline 8 & No & No & Yes & No & No & Yes & + & + & + & + \\
\hline 9 & No & No & Yes & Yes & Yes & No & - & + & - & + \\
\hline 10 & No & No & Yes & No & No & Yes & - & + & - & + \\
\hline 11 & No & Yes & Yes & No & No & Yes & + & + & + & + \\
\hline 12 & No & No & Yes & No & No & Yes & + & + & NA & NA \\
\hline 13 & No & No & Yes & Yes & Yes & No & - & - & - & - \\
\hline 14 & Yes & Yes & Yes & No & No & Yes & - & + & - & + \\
\hline 15 & No & Yes & Yes & No & No & Yes & + & + & + & + \\
\hline 16 & No & No & Yes & Yes & No & Yes & - & + & NA & NA \\
\hline 17 & Yes & No & No & Yes & No & Yes & - & + & - & + \\
\hline 18 & Yes & Yes & Yes & No & No & Yes & - & + & NA & NA \\
\hline 19 & No & Yes & Yes & No & No & Yes & + & + & + & + \\
\hline 20 & No & No & Yes & No & No & Yes & + & + & + & + \\
\hline 21 & No & No & Yes & No & No & Yes & - & + & - & + \\
\hline 22 & Yes & Yes & Yes & No & No & Yes & - & + & NA & NA \\
\hline 23 & No & No & Yes & No & No & Yes & - & + & - & + \\
\hline 24 & No & No & Yes & Yes & No & No & - & + & NA & NA \\
\hline 25 & No & Yes & Yes & No & No & Yes & + & + & + & + \\
\hline
\end{tabular}

NA Not applied. 

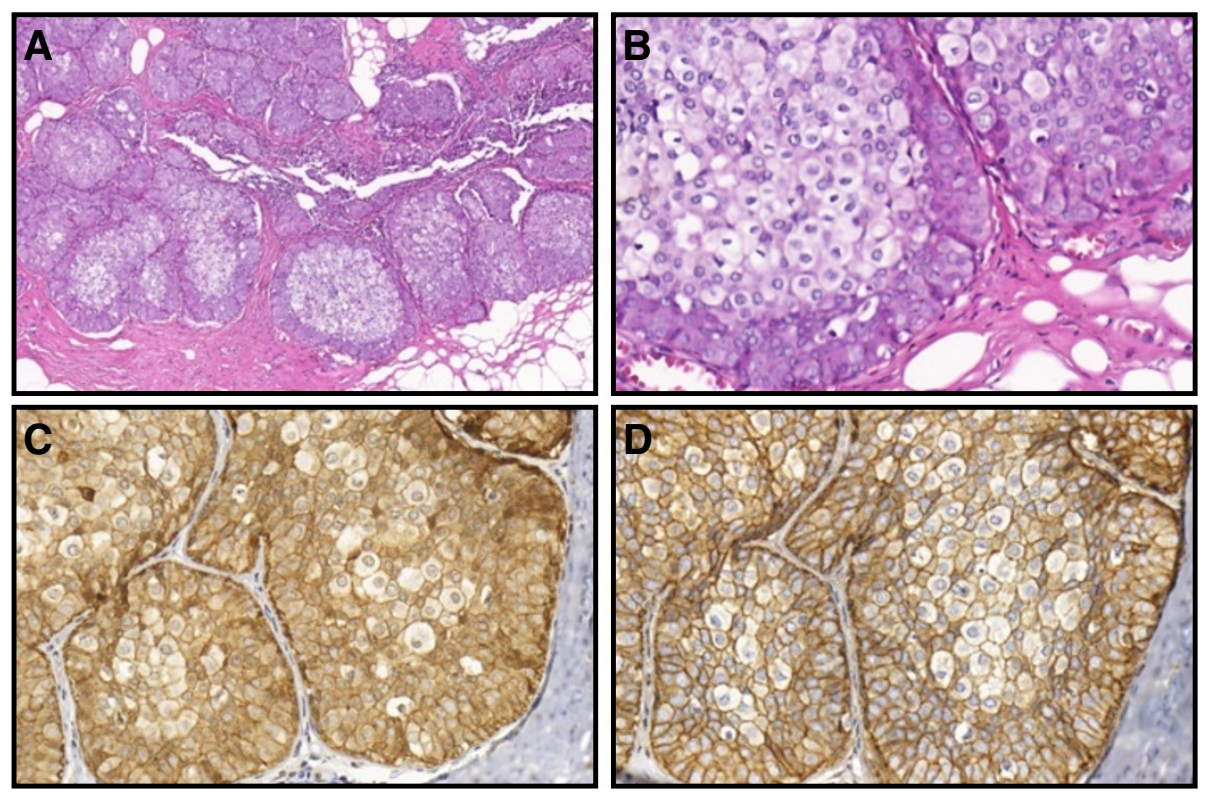

Figure 2 Case \# 8: Carcinoma in situ with mixed pattern (CISM) showing dual cell population (Group 2) stained for hematoxylin and eosin (A - 100x, B - 400x). A stronger positive membrane staining for E-cadherin ( $\mathbf{C}-400 x)$ and $\beta$-catenin ( $\mathbf{D}-400 x)$ can be appreciated in the outer layer of cells of ductal pattern. A weaker staining is seen in cells of lobular pattern present in the center of the units.

xed with groups of low nuclear grade dyshesive cells, in a mosaic pattern. Of these, $11(57.9 \%)$ presented positive immunohistochemistry for E-cadherin and $\beta$-catenin. In these cases, solid architecture with low-grade cytology was the most common morphological pattern. Eight of these cases (42.1\%) presented the mixed immunophenotype and in four of them, the mixed pattern resulted from a "collision" of the lesions showing areas positive and areas negative for both markers in the same duct-lobular unit (Figure 3).

Two cases presented the lobular architectural pattern with nuclear pleomorphism and two cases presented mixed cytology and nuclear pleomorphism. The last two cases were considered as mixed immunophenotype. Of the two cases that presented comedonecrosis and nuclear pleomorphism, one was completely negative for both markers (Figure 4) and the other presented cells positive and cells negative for both markers (Table 2).

\section{Discussion}

In this study, we sought to evaluate the expression of Ecadherin and $\beta$-catenin for the immunophenotypical characterization of CISM. We also searched for potential morphological patterns that could help in the diagnosis of different types of CISM lesions. We adopted the morphological classification described by Jacobs et al. that defines CISM as "carcinomas with indeterminate features"[3]. According to this classification CISM lesions are divided in three main groups, namely: (I) presence of necrosis, (II) cytology and / or mixed architecture, and (III) nuclear polymorphism. This classification is highly reproducible and addresses the main morphological groups described in our study.

A total of 25 CISM cases were evaluated in this study. The most common morphological pattern of lesions identified belonged to group (II) with 19 out of 25 cases (76\%), followed by group (III) (2/25 cases - 8\%), and overlapping patterns between groups (I) and (II) $(2 / 25$ cases - 8\%) and groups (II) and (III) (2/25 cases - $8 \%$ ). Our findings are in agreement with those reported by Jacobs et al. who observed, in 28 cases of CISM, 60\% of the lesions in group (II) (17/28 cases), $21 \%$ in group (I) (5/28 cases), and $18 \%$ in group (III) (5/28 cases).

However, it is noteworthy that the terminology and morphologic criteria used for the diagnosis of CISM are heterogeneous. Fisher et al. termed it as "ductolobular carcinoma in situ" lesions with monomorphic cells with foci of necrosis or cribriform pattern [4]. Acs et al. described 14 cases of CISM referring to the lesions as "with ductal carcinoma in situ and lobular features" and adopted, as a diagnostic criteria, LN in situ lesions with cytological and architectural patterns, with central areas of comedonecrosis or lobules, or large duct units populated by non-cohesive cells with marked nuclear pleomorphism [19]. Maluf et al. analyzed 12 cases of "solid low grade carcinoma in situ of the breast" and included "low-grade solid DCIS, LCIS and DCIS and LCIS associated with invasive carcinomas of any type. Cases showing only unequivocal areas of LCIS or DCIS of nonsolid type were excluded" [20].

Even among experts in the pathology of breast tumors, the descriptions of these lesions are divergent. Page and 

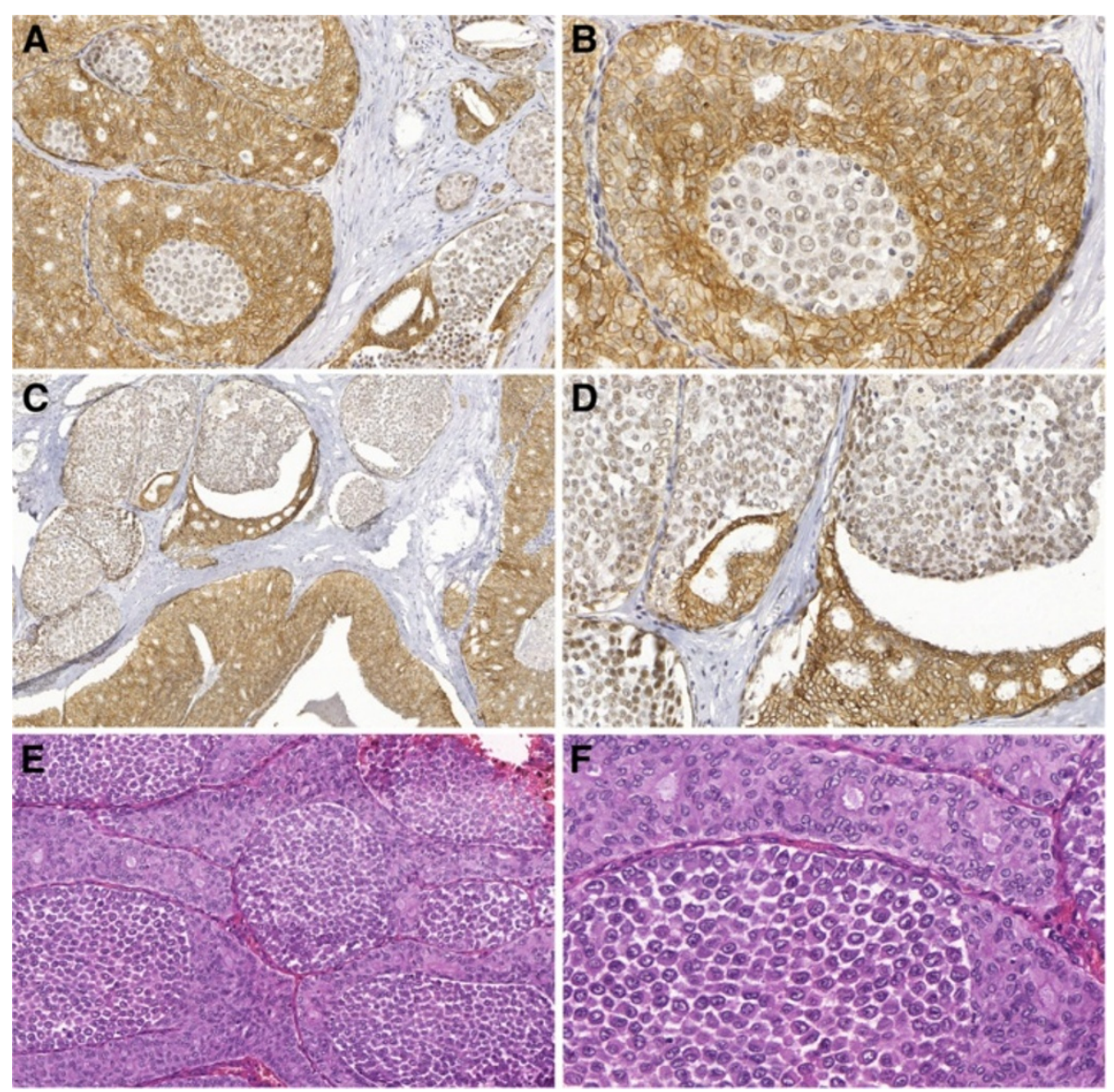

Figure 3 Case \# 16: Carcinoma in situ with mixed pattern (CISM) showing dual cell population stained for hematoxylin and eosin, involving a papilloma and adjacent ducts. Areas of pleomorphic lobular pattern show discohesive atypical cells (arrows). Areas of "ductal" pattern show proliferation of cohesive cells with hyperchromatic nuclei forming secondary, rounded, and uniform lumens (arrowheads), (A, 200X and $\mathbf{B}, 400 \times)$. A mixed pattern resulted from a "collision" of both cell types in the same duct-lobular unit. "Ductal" cells are positive for E-cadherin (arrowheads) and lobular cells are negative (C and E- 200x, D and $\mathbf{F}-400 x$ ).

Anderson state that in most cases an attempt should be made to classify the lesions as LN or DCIS [21]. However, on rare occasions this might not be possible and the diagnosis of "in situ carcinoma of ductal or lobular type" needs to be made. These authors recommend that if more than one focus of necrosis is found, the lesion should not be classified as LN. Rosen describes two main types of CISM: "concurrent intraductal and lobular carcinoma in situ" for lesions that present a cytology of lobular pattern and distended ducts and central necrosis or calcifications, and "coexistent intraductal and lobular carcinoma in situ in a single duct-lobular unit." The author uses this description to refer to the more unusual intraductal lesions characterized by the presence of two distinct architectural and cytological patterns [22].

Recently, in situ lesions with lobular cytological features of classic LCIS but with marked nuclear pleomorphism, comedonecrosis, and with or without apocrine cytology have been described as pleomorphic LCIS [1]. Some reports suggest that these variants are more aggressive than classic LN and a surgical treatment similar to that applied to DCIS is recommended. However, there are no prospective epidemiological studies showing that these variants have different clinical significance and appropriate management of pleomorphic LCIS is currently uncertain [1].

In our series, we observed a frequent association between immunophenotype and morphology (cytoarchitectural features). Lesions in group (II), with solid architecture and low-grade cytology, were more often associated with expression of E-cadherin. Our data differ from those reported by Acs et al., in which no expression of E-cadherin was observed in the 14 CISM cases analyzed. The most frequent morphological pattern observed in that study was presence of lobular cytology with comedonecrosis $(\mathrm{n}=9)$ [19]. Maluf et al. analyzed 12 CISM cases and detected E-cadherin expression in five, while another five cases showed no expression of the protein and two presented a mixed population of cells in this 

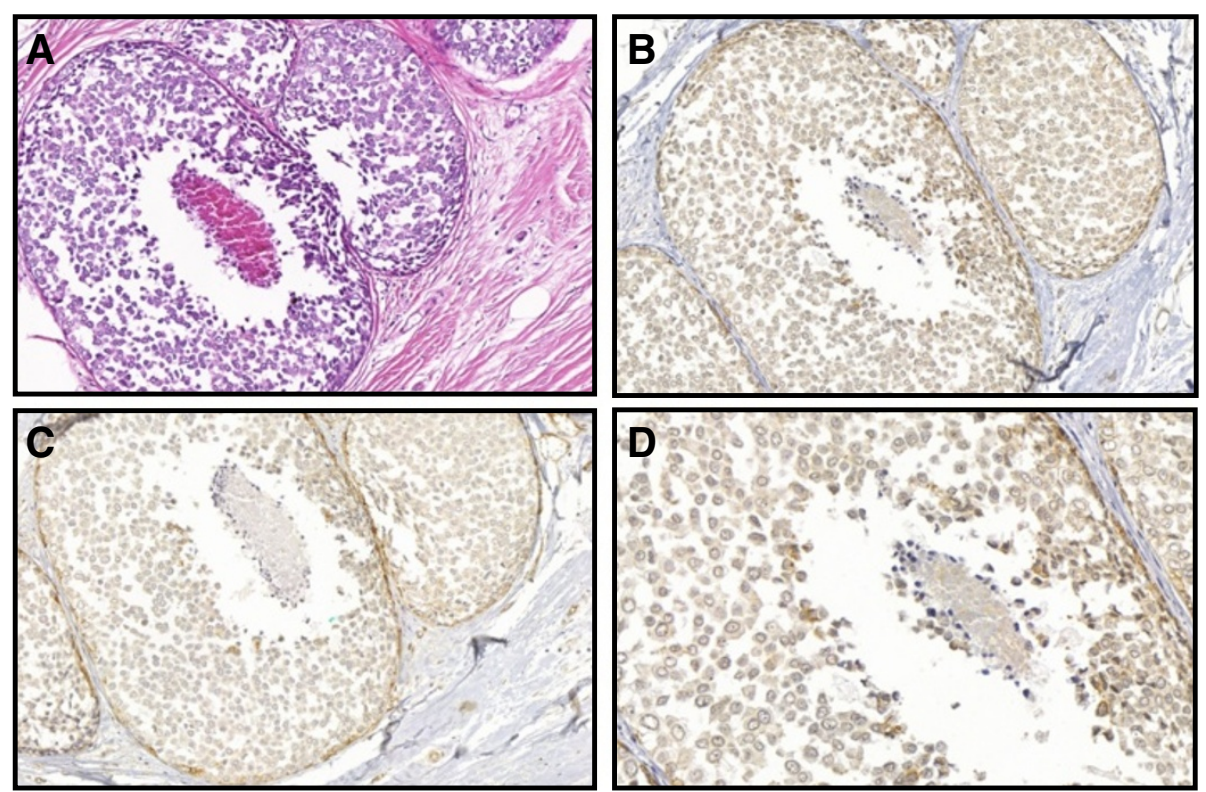

Figure 4 Case \# 13: Pleomorphic lobular carcinoma in situ showing discohesive atypical cells, with nuclear pleomorphism and comedonecrosis. Hematoxylin and eosin (A - 100x). Lobular cells are negative for E-cadherin (B - 100x; D - 400x) and for $\beta$-catenin (C - 100x).

regard. These authors did not observe the prevalence of a specific morphological pattern over others [20]. Similarly to the study by Jacobs et al., lesions in group (II) were the most frequent lesion associated with expression of E-cadherin in our study, however we observed them at a higher frequency. A dual cell population in the same terminal duct-lobular unit was observed in four cases. This is likely due to the coexistence of LN and DCIS in the same terminal duct-lobular unit.

Since first reported, the immunohistochemical reaction of E-cadherin has been proposed as an aiding tool in the differential diagnosis between ductal and lobular lesions, either invasive or in situ. However, it should be noted that up to $15 \%$ of lobular lesions may exhibit aberrant expression of E-cadherin and thus, the lack of E-cadherin expression should not be used as the sole criterion for LN diagnosis [12]. Choi et al. observed variability in the immunohistochemical staining of

Table 2 Category morphology and immunophenotype for E-cadherin of carcinoma in situ with mixed pattern

\begin{tabular}{lcccc}
\hline Morphology & Cases & \multicolumn{3}{c}{ E-cadherin } \\
\cline { 3 - 5 } & & Positive & Negative & Mixed \\
\hline Group 1 & 0 & 11 & 0 & 0 \\
Group 2 & 19 & 0 & 0 & 8 \\
Group 3 & 2 & 0 & 0 & 2 \\
Group 2 and 3 & 2 & 0 & 1 & 2 \\
Group 1 and 3 & 2 & 11 & 1 & 0 \\
Total & 25 & & & 13 \\
\hline
\end{tabular}

E-cadherin, and detected abnormal staining patterns, both in ductal and lobular lesions, making the differential diagnosis between in situ lobular and invasive lesions very difficult through immunohistochemistry [10]. An alternative to reduce this interference and improve diagnosis is the combined use of immunohistochemical markers of the catenin pathway. Using IHC and molecular biology techniques Da Silva et al. analyzed three cases presenting morphological characteristics and genotyping that agreed with invasive lobular carcinoma, with nonetheless aberrant expression of E-cadherin. Of these three cases, two did not express $\beta$-catenin, indicating that the formation of the cadherin-catenin complex, which is required for the normal function of the cell and maintenance of tissue architecture, including cell adhesion, failed [12,23]. In our study, we observed that expression of E-cadherin agreed with expression of $\beta$-catenin in all cases here observed.

Other explanations for the abnormal expression of E-cadherin found in other studies may be related to technical difficulties and pitfalls that may occur during the different stages in the immunohistochemical reaction. In our study, we had some difficulties in the pre-analytical reaction such as material loss and weak staining in some cases. This may reflect the fact that we used specimens coming from the routine diagnosis laboratory of a general hospital; and other cases were sent to us for a second opinion. In many cases, there was no control of the pre-analytical phase or standardization of time of formalin fixation and unbuffered formalin was used. Goldstein et al. showed that the reactivity level varies 
with the number of blocks and thickness of the sample sections in the pre-analytical process [2]. Different clones of antibodies against E-cadherin and different antigens may also have an effect on the quality of the immunohistochemical staining. A comparison between two types of antibodies revealed discrepancy in the staining of lobular lesions in $6.4 \%$ of the cases [7]. Finally, there is a lack of consensus regarding the interpretation of the positivity of immunohistochemical staining of E-cadherin. The established cutoff of a positive signal varies between basal membrane expression and presence of any positivity to $20 \%$ of expressing cells $[12,23]$. Semiquantitative evaluations of the intensity of staining and association of different criteria forming scores of staining intensity have also been proposed [19].

Other immunohistochemical markers have been suggested to aid in the diagnosis of CISM. The p120 catenin is an intracellular protein that promotes the binding between the complex of catenins and cell cytoskeleton. When E-cadherin expression is absent, p120 catenin is dispersed in the cytoplasm, which explains its expression in the cytoplasm in LN, and in the membrane in DCIS $[23,24]$.

\section{Conclusions}

The immunophenotypic characterization of carcinomas in situ using E-cadherin and $\beta$-catenin, combined with the analysis of cytological and architectural patterns, is a useful tool for the morphological and immunophenotypical classification of CISM. However, a negative staining for these markers should not be used as the sole criterion of lobular phenotype because aberrant expression in lobular neoplasia and loss of expression in ductal cancers can both occur.

\footnotetext{
Abbreviations

ALH: Atypical lobular hyperplasia; CISM: Carcinoma In Situ with mixed pattern; DCIS: Ductal carcinoma In Situ; LN: Lobular neoplasia; LCIS: Lobular carcinoma In Situ; IHC: Immunohistochemistry; E-cadherin: Human epithelial cadherin; PLCIS: Pleomorphic lobular carcinoma In Situ; UFMG: Federal University of Minas Gerais.
}

\section{Competing interests}

The authors declare that they have no competing interests.

\section{Authors' contributions}

DSG conceived the study, participated in the histological review, and drafted the manuscript. SSP participated in the design of the study. RMG: Performed the immunohistochemistry reactions. $H G$ participated in design and coordination of the study, participated in the histological review, and drafted and reviewed the manuscript. All authors have read and approved the final manuscript.

\section{Acknowledgments}

This work was supported in part by Fundação de Amparo à Pesquisa de Minas Gerais (FAPEMIG), Conselho Nacional de Desenvolvimento Científico e Tecnológico (CNPq), and Coordenação de Aperfeiçoamento de Pessoal de Nível Superior (CAPES).

This manuscript was reviewed by a professional science editor and by a native English-speaking copy editor to improve readability.

\section{Author details}

'Breast Pathology Laboratory, School of Medicine, Federal University of Minas Gerais (UFMG), Av. Professor Alfredo Balena, 190, Belo Horizonte, Minas Gerais 30130-100, Brazil. 'Laboratory of Investigative Pathology, A.C. Camargo Hospital, São Paulo-SP, Brazil.

Received: 17 April 2013 Accepted: 12 June 2013

Published: 9 July 2013

\section{References}

1. Lakhani SR, Ellis IO, Schnitt SJ, Tan PH, van de Vijver MJ, World Health Organization, International Agency for Research on Cancer: WHO classification of tumours of the breast. 4th edition. Lyon: IARC; 2012.

2. Goldstein NS, Bassi D, Watts JC, Layfield L, Yaziji H, Gown AM: E-cadherin reactivity of 95 noninvasive ductal and lobular lesions of the breast. Implications for the interpretation of problematic lesions. Am J Clin Pathol 2001, 115:534-542.

3. Jacobs TW, Pliss N, Kouria G, Schnitt SJ: Carcinomas in situ of the breast with indeterminate features: role of E-cadherin staining in categorization. Am J Surg Pathol 2001, 25:229-236.

4. Fisher B, Costantino JP, Wickerham DL, Redmond CK, Kavanah M, Cronin WM, Vogel V, Robidoux A, Dimitrov N, Atkins J, et al: Tamoxifen for prevention of breast cancer: report of the national surgical adjuvant breast and bowel project P-1 study. J Natl Cancer Inst 1998, 90:1371-1388.

5. Schnitt SJ, Morrow M: Lobular carcinoma in situ: current concepts and controversies. Semin Diagn Pathol 1999, 16:209-223.

6. Lakhani SR, Audretsch W, Cleton-Jensen AM, Cutuli B, Ellis I, Eusebi V, Greco M, Houslton RS, Kuhl CK, Kurtz J, et al: The management of lobular carcinoma in situ (LCIS). Is LCIS the same as ductal carcinoma in situ (DCIS)? Eur J Cancer 2006, 42:2205-2211.

7. Liberman L: Clinical management issues in percutaneous core breast biopsy. Radiol Clin North Am 2000, 38:791-807.

8. Nagi CS, O'Donnell JE, Tismenetsky M, Bleiweiss IJ, Jaffer SM: Lobular neoplasia on core needle biopsy does not require excision. Cancer 2008, 112:2152-2158.

9. Bratthauer GL, Moinfar F, Stamatakos MD, Mezzetti TP, Shekitka KM, Man YG, Tavassoli FA: Combined E-cadherin and high molecular weight cytokeratin immunoprofile differentiates lobular, ductal, and hybrid mammary intraepithelial neoplasias. Hum Pathol 2002, 33:620-627.

10. Choi YJ, Pinto MM, Hao L, Riba AK: Interobserver variability and aberrant E-cadherin immunostaining of lobular neoplasia and infiltrating lobular carcinoma. Mod Pathol 2008, 21:1224-1237.

11. Gomes DS, Balabram D, Porto SS, Gobbi H: Lobular neoplasia: frequency and association with other breast lesions. Diagn Pathol 2011, 6:74.

12. Da Silva L, Parry S, Reid L, Keith P, Waddell N, Kossai M, Clarke C, Lakhani SR, Simpson PT: Aberrant expression of E-cadherin in lobular carcinomas of the breast. Am J Surg Pathol 2008, 32:773-783.

13. Goldstein NS, Kestin LL, Vicini FA: Clinicopathologic implications of Ecadherin reactivity in patients with lobular carcinoma in situ of the breast. Cancer 2001, 92:738-747.

14. Baranwal S, Alahari SK: Molecular mechanisms controlling E-cadherin expression in breast cancer. Biochem Biophys Res Commun 2009, 384:6-11.

15. Andrews $J \mathrm{~L}, \mathrm{Kim} A C$, Hens JR: The role and function of cadherins in the mammary gland. Breast cancer res 2012, 14:203.

16. Wangefjord S, Brandstedt J, Lindquist KE, Nodin B, Jirstrom K, Eberhard J: Associations of beta-catenin alterations and MSI screening status with expression of key cell cycle regulating proteins and survival from colorectal cancer. Diagn Pathol 2013, 8:10.

17. Cheng $H$, Liang $H$, Qin Y, Liu Y: Nuclear beta-catenin overexpression in metastatic sentinel lymph node is associated with synchronous liver metastasis in colorectal cancer. Diagn Pathol 2011, 6:109.

18. Tsanou E, Peschos D, Batistatou A, Charalabopoulos A, Charalabopoulos K: The E-cadherin adhesion molecule and colorectal cancer. A global literature approach. Anticancer Res 2008, 28:3815-3826.

19. Acs G, Lawton TJ, Rebbeck TR, LiVolsi VA, Zhang PJ: Differential expression of E-cadherin in lobular and ductal neoplasms of the breast and its biologic and diagnostic implications. Am J Clin Pathol 2001, 115:85-98.

20. Maluf HM, Swanson PE, Koerner FC: Solid low-grade in situ carcinoma of the breast: role of associated lesions and E-cadherin in differential diagnosis. Am J Surg Pathol 2001, 25:237-244. 
21. Page DL, Anderson TJ: Diagnostic histopathology of the breast. Edinburgh; New York: Churchill Livingstone; 1987.

22. Rosen PP: Rosen's breast pathology. 3rd edition. Philadelphia: Lippincott Williams \& Wilkins; 2008.

23. Dabbs DJ, Bhargava R, Chivukula M: Lobular versus ductal breast neoplasms: the diagnostic utility of p120 catenin. Am J Surg Pathol 2007, 31:427-437

24. Sarrio D, Perez-Mies B, Hardisson D, Moreno-Bueno G, Suarez A, Cano A, Martin-Perez J, Gamallo C, Palacios J: Cytoplasmic localization of p120ctn and E-cadherin loss characterize lobular breast carcinoma from preinvasive to metastatic lesions. Oncogene 2004, 23:3272-3283.

doi:10.1186/1746-1596-8-114

Cite this article as: Gomes et al: Usefulness and limitations of

$\mathrm{E}$-cadherin and $\beta$-catenin in the classification of breast carcinomas in situ with mixed pattern. Diagnostic Pathology 2013 8:114.

\section{Submit your next manuscript to BioMed Central and take full advantage of:}

- Convenient online submission

- Thorough peer review

- No space constraints or color figure charges

- Immediate publication on acceptance

- Inclusion in PubMed, CAS, Scopus and Google Scholar

- Research which is freely available for redistribution 